\title{
Interlúdio - Diminuendo e crescendo in blue Improvisação de Paul Gonsalves
}

\section{Duke Ellington}

Transc. e ed. de Leonardo Barreto Linhares a partir da gravação ao vivo realizada no

Chorus 1 Legato Pasadena Concert em 1953

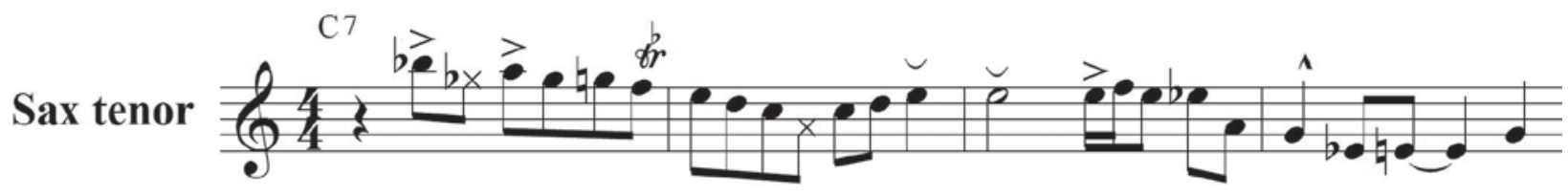

F 7

C7

G 7

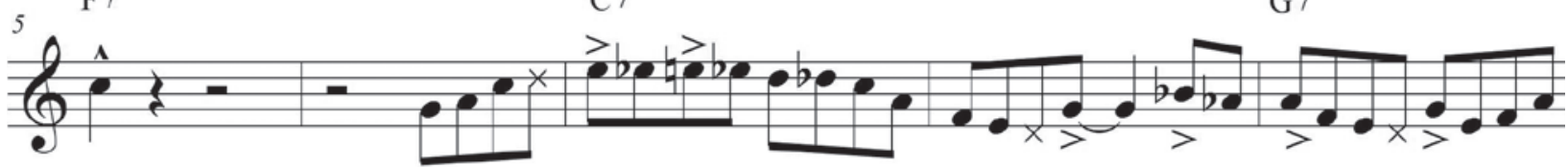

F 7

C7

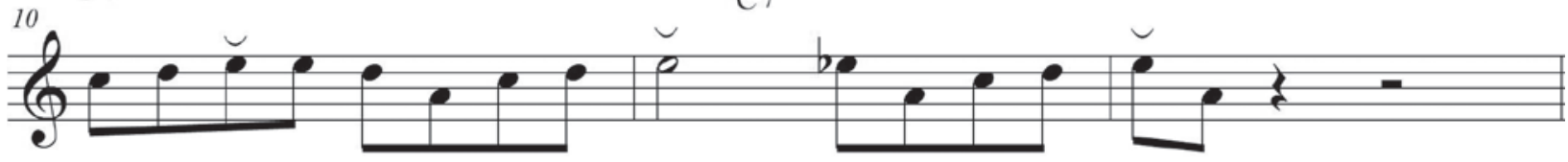

Chorus 2

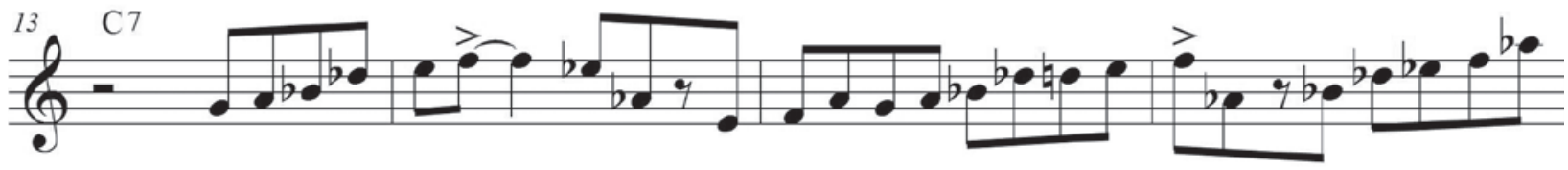

F 7

C7

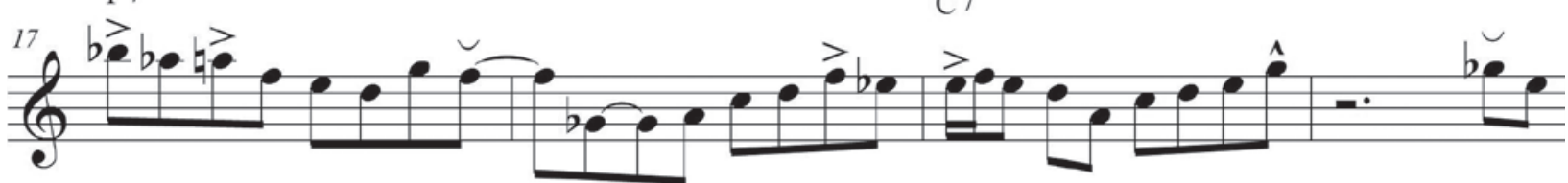

G 7

F7

C7

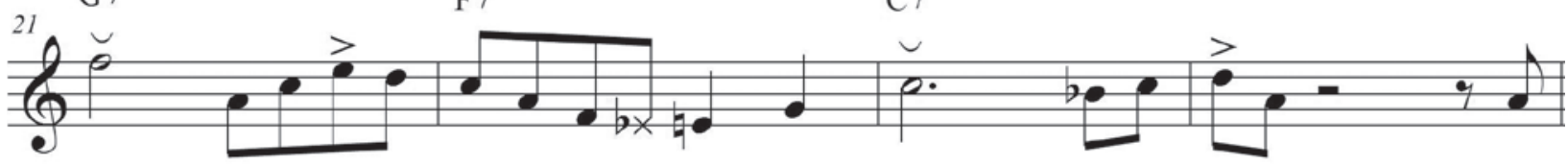


Chorus 3

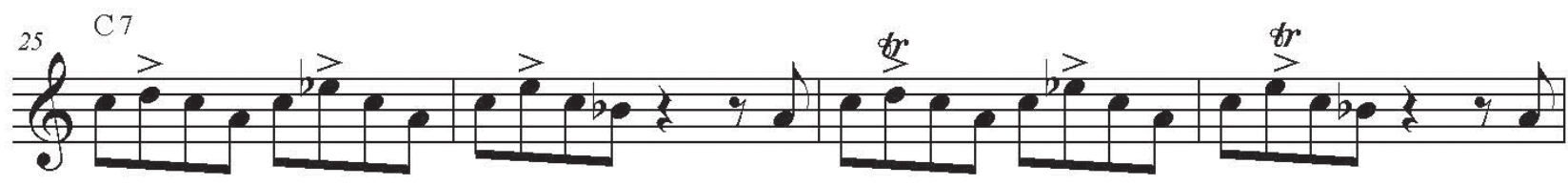
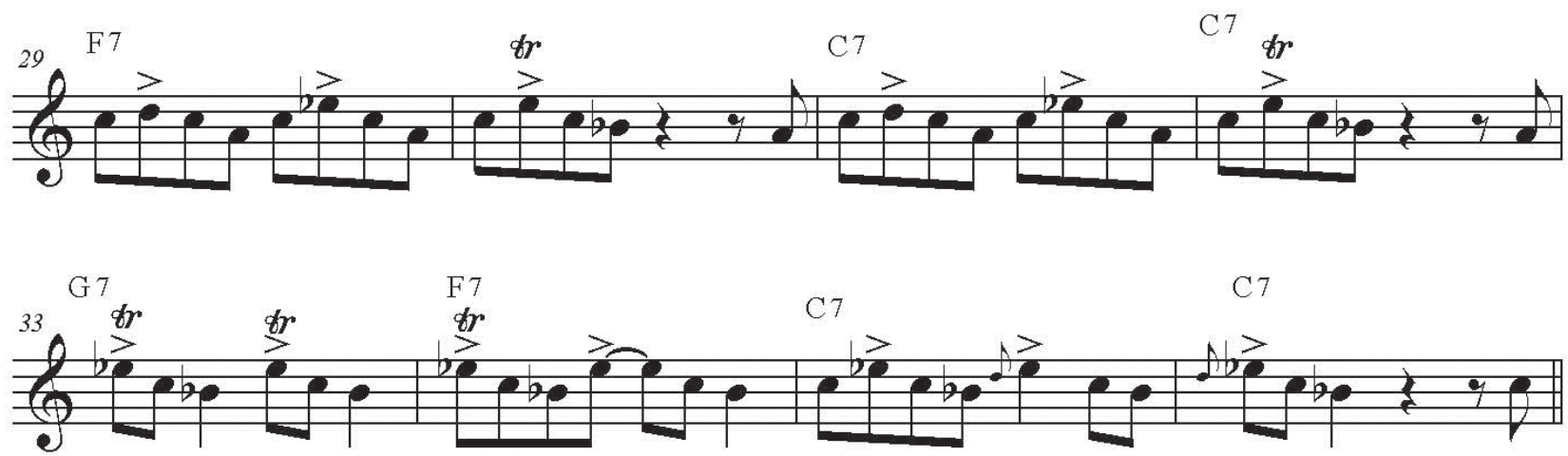

Chorus 4
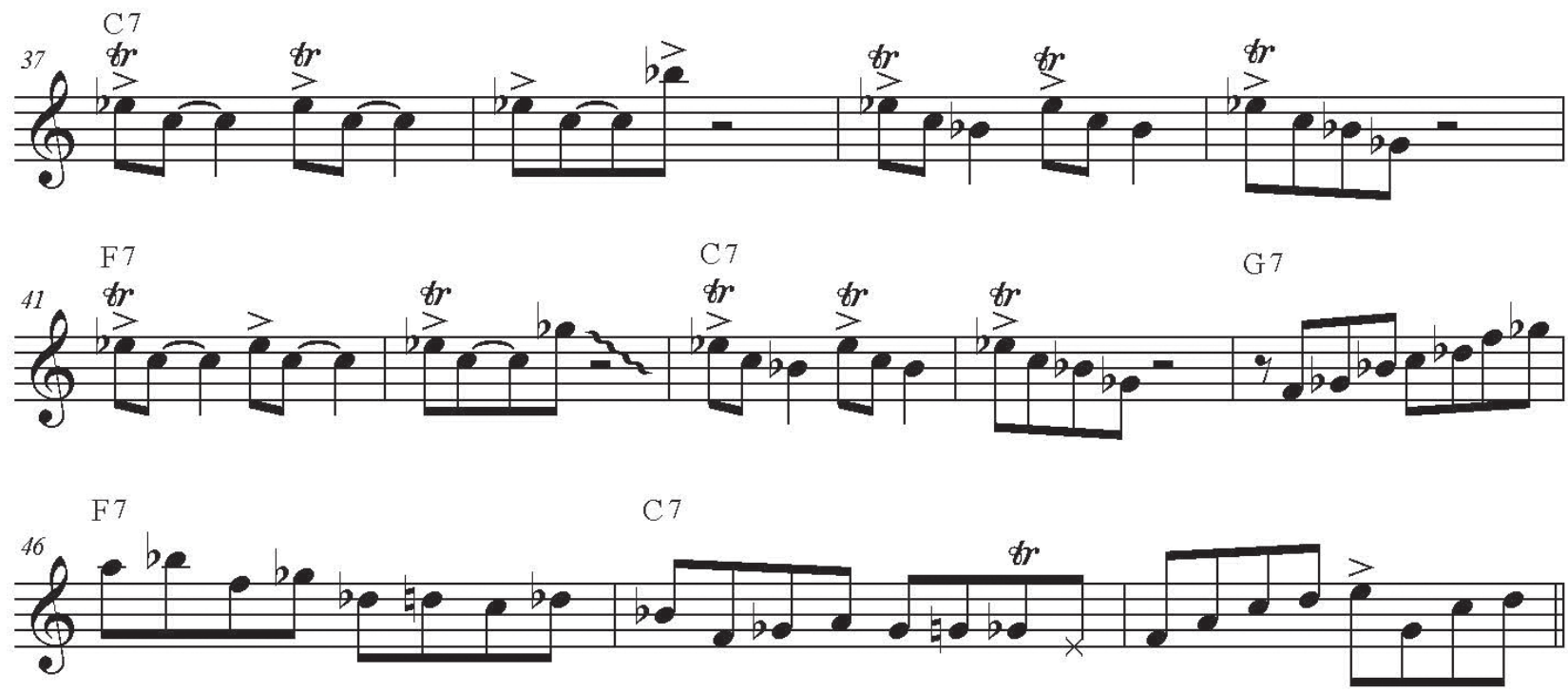

Chorus 5

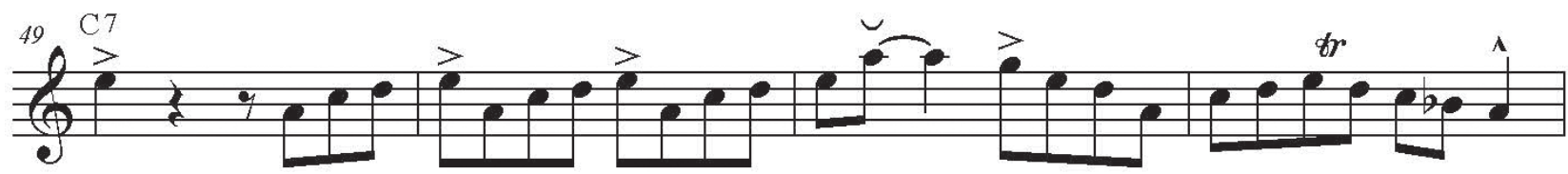


F7

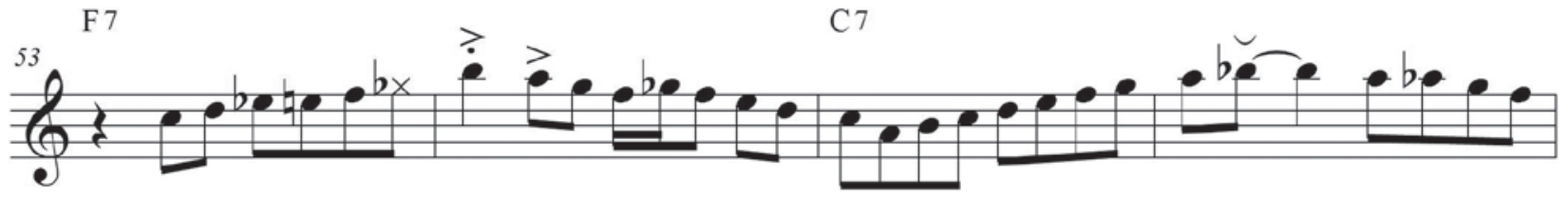

F 7

C7

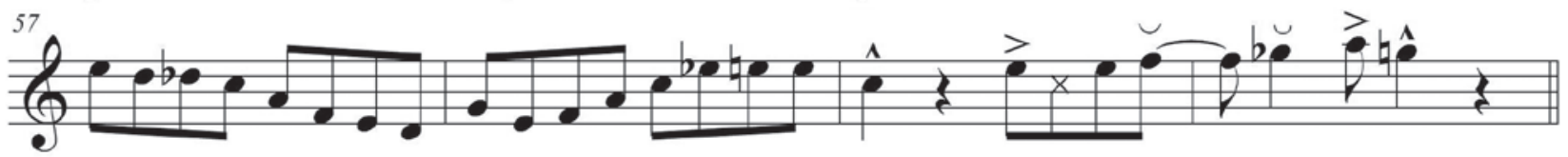

Chorus 6

C 7

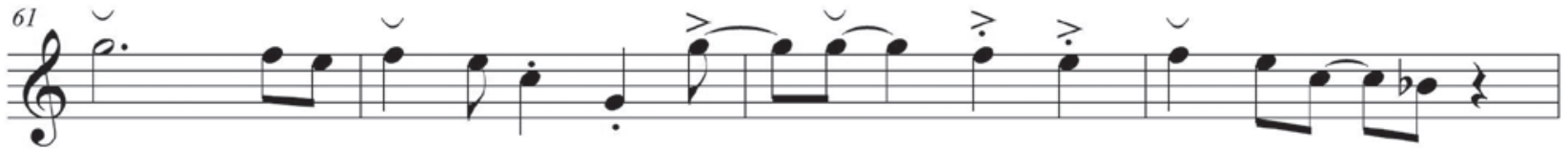

F 7

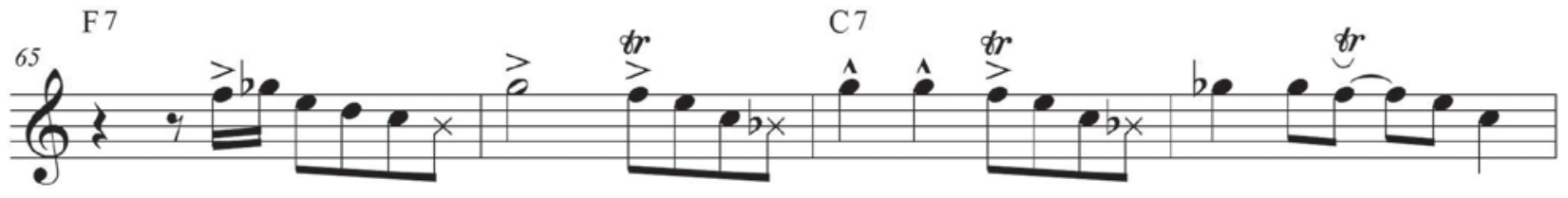

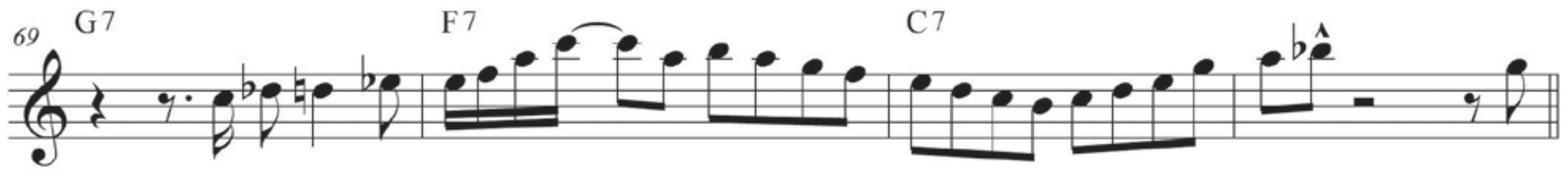

Chorus 7

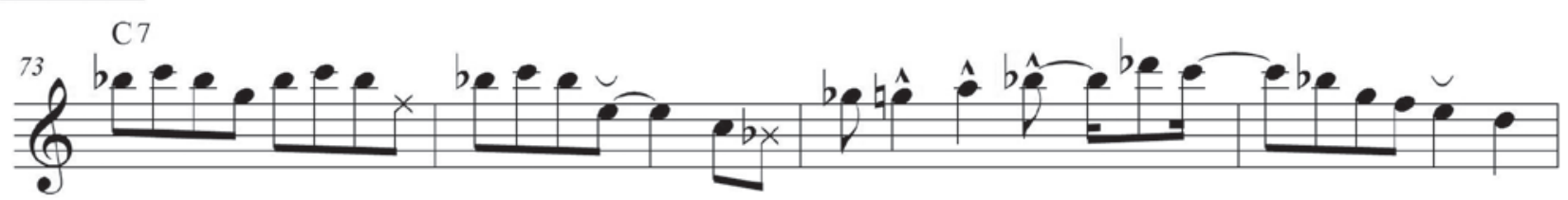

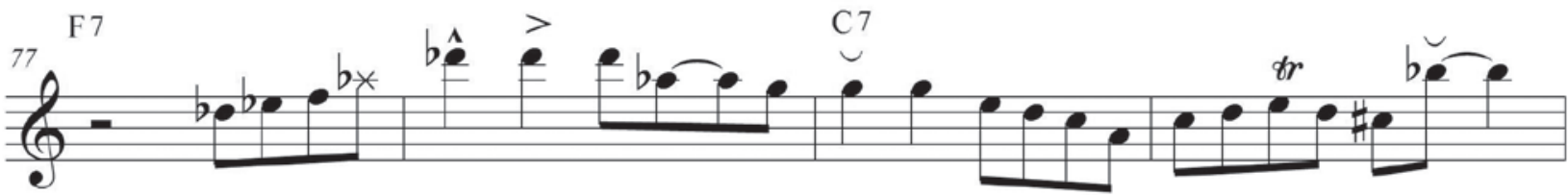

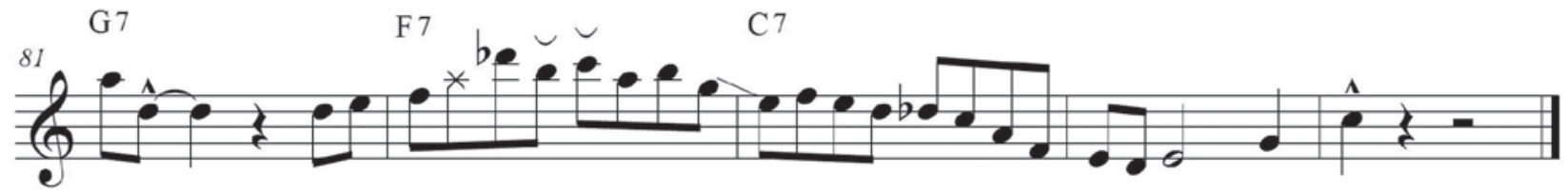


Glossário de efeitos, articulações e acentuações do jazz (LAWN, 1995).

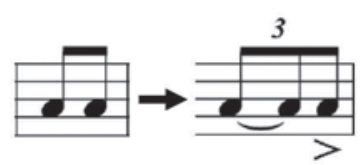

Swing - Duas colcheias devem ser tocadas dessa forma de acordo com a caracterização do gênero.

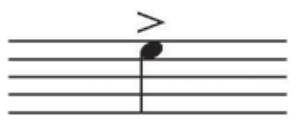

Heavy accent - Valor integral da nota acentuando, pesado.

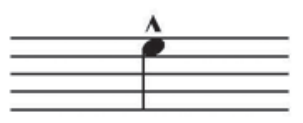

Heavy accent - Tocar metade do valor da nota, pesado.

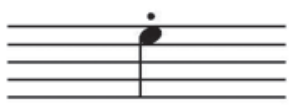

Staccato - Curto sem ser pesado.

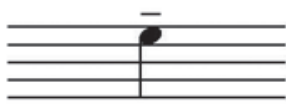

Legato tongue - Valor integral da nota, sem acentuação.

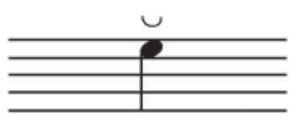

Bend - Tocar a nota na afinação correta, abaixar a afinação e voltar na afinação inicial.

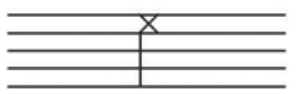

Ghost note - Nota com altura indefinida.

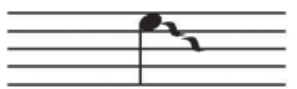

Short spill - Terminar a nota via escala cromática ou diatônica, aproximadamente uma terça abaixo.

Nenhuma nota deve ser ouvida individualmente.

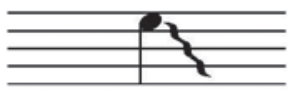

Long Spill - Terminar a nota via escala cromática ou diatônica, em uma nota mais distante. Nenhuma nota deve ser ouvida individualmente.

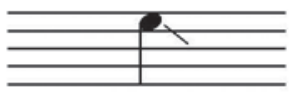

Short gliss down - Terminar a nota descendo aproximadamente três notas abaixo. Nenhuma nota deve ser ouvida individualmente.

Obs1: as acentuações e articulações decorrentes do swing não foram explicitadas na partitura. Foram anotados apenas os efeitos e acentuações decorrentes da interpretação do fraseado pelo músico.

Obs2: A harmonia transcrita foi simplificada, sendo notados somente os acordes básicos com sétima menor da sequência dos blues de 12 compassos.

\section{Referência:}

LAWN, Richard. The jazz ensemble director's manual: a handbook of practical methods and materials for the educator. Oskaloosa: C.L. Barnhouse Company, 1995. 